\title{
Evaluating the Relationship between Job Burnout and Empowerment of Female Teachers in Secondary Schools of the Education System in Shiraz City (District 2)
}

\author{
Ameneh Rasekh \\ Department of Educational Sciences and Psychology, Payamenoor University, \\ Pobox 19395 -3697 Tehran, IR of Iran
}

Tayebeh Safaei

Assistant professor, Department of Educational Sciences and Psychology, Payamenoor University, Pobox 19395 -3697 Tehran, IR of Iran

\section{Doi:10.5901/mjss.2016.v7n4s1p95}

\section{Abstract}

The purpose of this research was to evaluate the relationship between job burnout and empowerment. The statistical population of this research was female teachers who work in secondary schools of District 2 in the Education system of Shiraz City in 2014-15 (1111 people). A sample of 189 people was selected by cluster sampling method using Krejcie and Morgan Table. This research has been done through a descriptive (surveying-correlational) method. Spreitzer Empowerment Questionnaire and Burnout Questionnaire of Maslach and Jackson have been used to collect data. In this way, empowerment and job burnout scales were confirmed through Cronbach's alpha coefficient with the reliability of 0.78 and 0.86 , respectively. Pearson correlation coefficient and multiple regression were used to analyze the data. The results are as follows: There is a significant negative relationship between empowerment and burnout. There is a significant negative relationship between empowerment and emotional exhaustion, between empowerment and depersonalization, and between empowerment and reduced personal accomplishment, autonomy, effectiveness, meaningfulness and merit of female teachers. In addition, the regression analysis for predicting job burnout from empowerment showed that empowerment explains only $7.4 \%$ of job burnout variance that is a small amount. In other words, the prediction accuracy is low.

Keywords: Job burnout, empowerment, emotional exhaustion, reduced personal accomplishment, autonomy, effectiveness, meaningfulness.

\section{Introduction}

Empowerment is the process of empowering people. In this process, we help employees to improve their self-esteem and to prevail their sense of failure and helplessness. Empowerment in this meaning leads to the mobilization of people's internal motivations (Whetten and Cameron, 1996, translation Avraei 1385: 24). Empowerment also encourages people to participate more in decisions that affect their activities. In this way, we can provide opportunities for people to show that they can create good ideas and to realize it (Smith, 2000, translation Abtahi and Abbasi, 1386: 1).

Job is a part of life that has attracted the attention of many researchers. Regardless of making money, job satisfies a number of people's basic needs such as mental and physical activity, social contact, feelings of self-worth, and confidence and ability. However, it can also be a source of major stress (Powell, 1994; translated by Bakhsipour and Sabouri Moghadam, 1387: 116).

May be a satisfactory job, over time, become a source of dissatisfaction and lead to burnout (Ross and Altmayer, 1994; translated by Khajehpour, 2008, 68).

In today's world, capability, economic strength, and prosperity of any country depend on the efficient use of facilities, resources, and work force of the country. In this regard, whatever the workforce be more competent and more efficient, the development of that country in various economic and social fields will be more. It should be noted that the efficiency of each individual depends on various factors such as talent, intelligence, motivation, quality of used tools, required training and expertise, job conditions, and relieving exhaustion, etc. One of the major job issues that is seen in the form of reaction toward job and organizational pressures among the human service employees is job burnout phenomenon. There are different definitions about job burnout. For example, job burnout can be described as a reaction to chronic stress and response to pressures from job or organization (Saatchi, 2007: 164). 
The importance of exhaustion relieving methods is preventing burnout and exhaustion by appropriate solutions and treating this condition in case of burnout. Maslach and Jackson have defined this kind of exhaustion as a phenomenon that is made of three components of emotional exhaustion, depersonalization, and reduced personal accomplishment. Emotional exhaustion: It is the widespread feeling of exhaustion and distress caused by the emotional demands of the profession type in the person. Depersonalization: It is the negative attitudes or responses of the individual's competencies and lack of accomplishment in working. Reduced personal accomplishment: The reduction of individual competency and the sense of success in working with individuals (Evers. W. et al., 2005, translated by Amirkhani, 2009: 216).

Teachers due to the nature of their profession are faced with many problems such as voluminous work, academic drop of students, invalidity of their profession, insufficient salary, lack of student interest in studying, ignoring their needs from educational institutions, lack of their family support, overcrowded classes, promotion issues, and their role contradictions. All these problems can affect their mental health. The persistence of these problems increases their vulnerability and ultimately leads to burnout. In other words, job burnout is expressed as a long-term response to chronic emotional and interpersonal stressful factors in job (Hassani, 2002, 58). The purpose of this research is to evaluate the relationship between empowerment and job burnout among teachers in secondary schools of District 2 in educational system and to provide the required background and serious actions to empower schools with the aim of clarifying the relationship between empowerment and job burnout of teachers in schools and reducing teachers' burnout and increasing their ability. Given the above, in this research, the researcher aims to find out that what is the relationship between job burnout and empowerment of women teachers in first grade secondary schools?

Shojaei (2014) conducted a study to evaluate the effects of psychological empowerment on reducing job burnout by taking the role of perceived organizational support on insurance companies in Tehran. The results show that among the four components of psychological empowerment, meaningfulness, effectiveness, and being the decision maker; being the decision maker affects the perceived organizational support and perceived organizational support affects the job burnout reduction. In addition, the sense of significance and the being decision maker directly affects the burnout reduction. There is no report about the effect of competency on the perceived organizational support and the job burnout reduction. Fattah (2014) has conducted a research entitled the relationship between empowerment and quality of work life with job burnout in the education system employees of Tehran. The results showed that there is a significant negative relationship between empowerment and quality of work life with job burnout in the employees. There is also a negative relationship between different dimensions of work life and different aspects of empowerment and job burnout, but despite being negative, there is no significant relationship between emotional exhaustion and depersonalization with fair wage paying and between the variables of personal growth and the sense of independence. In addition, different aspects of empowerment and quality of work life separately could predict the employees' job burnout negatively.

Bahrami (2014) has conducted a research entitled the role of psychological empowerment and organizational commitment on job burnout of teachers. The results showed that psychological empowerment has a significant positive relationship with emotional exhaustion and depersonalization and it has a negative relationship with personal accomplishment. Organizational commitment also has a significant negative relationship with emotional exhaustion and depersonalization. In addition, the hierarchical regression analysis showed that psychological empowerment, emotional exhaustion and personal accomplishment, and organizational commitment could predict the emotional exhaustion. Damani (2010) in his thesis entitled "The relationship between empowerment and creativity and job burnout among elementary school teachers of Iranshahr City" concluded that there is a significant relationship between empowerment with creativity and job burnout. There is a significant relationship between empowerment with emotional exhaustion. There is a significant relationship between empowerment with depersonalization, and there is a significant relationship between empowerment with reduced personal efficiency.

Cavus and Demir (2010) in a research entitled the relationship between psychological empowerment and job burnout concluded that psychological empowerment has a positive relationship with emotional exhaustion and it has a negative relationship with personal accomplishment. O'Brien (2010) in his research concluded that there is a negative relationship between psychological empowerment and burnout, but psychological empowerment cannot act as an independent predictor of burnout.

\section{Research Methodology}

This research is an applied research and the descriptive correlation method is used according to the nature and objectives of the research. The statistical population of this research was the female teachers working in secondary schools of District 2 in the Education system of Shiraz City in 2014-15 who are about 1111 people. A sample of 189 people was selected by cluster sampling method using Krejcie and Morgan Table. In addition, two questionnaires were 
used as following to collect data:

1. Spritzer empowerment questionnaire: Empowerment questionnaire contains 15 questions that measure the aspects of the sense of significance, the sense of competence or self-efficacy, the sense of self-determination, the sense of impact and trust. Using exploratory factor analysis (EFA) method, Spritzer validated the questionnaire in two samples of industry and insurance organizations. He analyzed the data using structural equation modeling and LISREL software. The questionnaire was formed of the seven-point spectrum of Likert scale (from one to seven). Factor analysis was used to determine the construct structure. The reliability and internal consistency of the items in the questionnaire and variables are shown in the table, which shows the high reliability of the questionnaire.

2. Job Burnout Questionnaire: Maslach and Jackson (1986) questionnaire has been used to measure the job burnout of teachers. This questionnaire is used to measure burnout in human service jobs and it has 22 items and three dimensions of burnout, depersonalization, and reduced personal accomplishment.

Data analysis has been done using SPSS software and the Pearson correlation coefficient test was used to evaluate the relationship between the variables, and multiple regression was used for the intensity and direction of the relationship.

\section{Research Findings}

The general hypothesis: There is a relationship between job burnout and empowerment of female teachers in secondary schools of District 2 in the Education system of Shiraz City.

Pearson correlation matrix:

Table 1. Pearson correlation matrix (with a two-tailed significance level) for empowerment and job burnout

\begin{tabular}{|l|l|c|c|}
\hline Variable & Index variable & Empowerment & Job burnout \\
\hline \multirow{3}{*}{ Empowerment } & Pearson correlation coefficient & 1 & -0.277 \\
\cline { 2 - 4 } & Two-tailed significance level & & 0.000 \\
\cline { 2 - 4 } & Number & 189 & 189 \\
\hline \multirow{3}{*}{ job burnout } & Pearson correlation coefficient & -0.277 & 1 \\
\cline { 2 - 4 } & Two-tailed significance level & 0.000 & 189 \\
\cline { 2 - 4 } & Number & 189 & 189 \\
\hline
\end{tabular}

Pearson correlation coefficient matrix is used to test the hypothesis. Given that the significant level between empowerment and job burnout is less than 0.05 , thus there is a significant relationship between empowerment and job burnout. Pearson correlation coefficient indicates the intensity of this interaction equal to 0.277 . Considering the negativity of this coefficient, it is concluded that the relationship between empowerment and job burnout is reversed. This means that empowerment increases/decreases by increasing/decreasing job burnout.

Regression analysis to predict the job burnout from empowerment:

Dependent variable: job burnout

Independent variable: Empowerment

Equation of regression prediction:

Job burnout $=\mathrm{C}+(\mathrm{B} \times$ Empowerment $)$

In which, $C$ is a constant and $B$ is the regression coefficient.

Table 2. Variance analysis to predict job burnout (dependent variable) from empowerment (predictor variables)

\begin{tabular}{|l|c|c|c|c|c|}
\hline Source & Total squares & Degrees of freedom & Mean squares & $\mathrm{F}$ & Significance level \\
\hline Regression & $168 / 2$ & 1 & $168 / 2$ & $89 / 16$ & $000 / 0$ \\
\hline Residual & $414 / 25$ & 187 & $128 / 0$ & & \\
\hline Total & $582 / 27$ & 188 & & & \\
\hline
\end{tabular}

Significance of $F$ in the above table $F=16.89, d f=1,187, p=0.000<0.05$ ) indicate that there is a linear relationship between the dependent variable and the predictor variables. Thus, the regression is valid. 
Table 3. Regression analysis to predict the dependent variable of job burnout

\begin{tabular}{|l|c|c|c|c|}
\hline Predictor variables & $\mathrm{R}$ & $\mathrm{R}^{2}$ & $\mathrm{R}^{2}$ adjusted & Standard error \\
\hline Empowerment & $0 / 280$ & $0 / 079$ & $0 / 074$ & $0 / 358$ \\
\hline
\end{tabular}

In the above table, the adjusted $\mathrm{R}^{2}$ represents the dependent variable based on the predictor variables. In other words, empowerment can explain only $7.4 \%$ of the creativity variance that is very little. In other words, the prediction accuracy is low.

Table 4. Equation elements for the predictor of job burnout

\begin{tabular}{|l|c|c|c|c|}
\hline Independent variable predictor & B & Beta & t & Significant level. \\
\hline (constant) & $2 / 858$ & & $14 / 379$ & $0 / 000$ \\
\hline Empowerment & $0 / 2020$ & $0 / 280$ & $4 / 110$ & $0 / 000$ \\
\hline
\end{tabular}

In the above table, the constant amount and regression coefficient are obtained in the regression equation. Considering the obtained numbers, regression equation can be written as follows:

$\mathrm{C}=2.858$

$\mathrm{B}=0.202$

Job burnout $=2.858+(0.202 \times$ Empowerment $)$

This relationship indicates that for one unit increase in empowerment, the amount of creativity increases as much as 0.202 . The left column of the table indicates the significant level of each coefficient. This column shows that the significant level of $B$ coefficient is obtained 0.000 and less than 0.05 . Therefore, this coefficient has a significant effect on the regression equation. Similarly, the significant level of the constant coefficient is obtained 0.000 that is less than 0.05 . This means that its effect is significant.

\subsection{Secondary Hypotheses}

Sub-hypothesis 1: There is a relationship between emotional exhaustion and empowerment of female teachers. Correlation coefficient test was used to answer this hypothesis. The results have been inserted in Table (6).

Table 5. Correlation coefficient between emotional exhaustion and empowerment of female teachers

\begin{tabular}{|c|c|c|}
\hline & \multicolumn{2}{|l|}{ Empowerment } \\
\hline & Correlation coefficient & Significant level \\
\hline Emotional exhaustion & $-0 / 253$ & $0 / 000$ \\
\hline
\end{tabular}

With regard to the above table, the Pearson correlation between empowerment and emotional exhaustion is obtained 0.000 according to the significant level, which is smaller than 0.01 . The null hypothesis is rejected at the 0.01 level and the research hypothesis is confirmed. Therefore, there is a significant relationship between empowerment and emotional exhaustion at $99 \%$ confidence level. Pearson correlation coefficient is 0.253 . The negativity of this coefficient shows that the relationship between empowerment and job burnout is reversed.

Sub-hypothesis 2: There is a relationship between depersonalization and empowerment of female teachers.

Correlation coefficient test was used to answer this hypothesis. The results have been inserted in Table (7).

Table 6. Correlation coefficient between depersonalization and empowerment of female teachers

\begin{tabular}{|l|l|l|}
\cline { 2 - 3 } \multicolumn{1}{c|}{} & \multicolumn{2}{|l|}{ Empowerment } \\
\cline { 2 - 3 } \multicolumn{1}{c|}{} & Correlation coefficient & Significant level \\
\hline Depersonalization & $-0 / 125$ & $0 / 004$ \\
\hline
\end{tabular}

With regard to the above table, the Pearson correlation between empowerment and depersonalization is obtained 0.125 according to the significant level, which is smaller than 0.05 . Therefore, there is a significant relationship between empowerment and depersonalization at 95\% confidence level. 

teachers.

Sub-hypothesis 3: There is a relationship between reduced personal accomplishment and empowerment of female

Correlation coefficient test was used to answer this hypothesis. The results have been inserted in Table (8).

Table 7. Correlation coefficient between reduced personal accomplishment and empowerment of female teachers

\begin{tabular}{|l|l|l|}
\hline \multirow{2}{*}{} & Empowerment \\
\cline { 2 - 3 } & Correlation coefficient & Significant level \\
\hline \hline Reduced personal accomplishment & $-0 / 269$ & $0 / 000$ \\
\hline
\end{tabular}

With regard to the above table, the Pearson correlation between empowerment and reduced personal accomplishment is obtained 0.000 according to the significant level, which is smaller than 0.01 . The null hypothesis is rejected at the 0.01 level and the research hypothesis is confirmed. Therefore, there is a significant relationship between empowerment and reduced personal accomplishment at $99 \%$ confidence level. Pearson correlation coefficient is 0.269 . The negativity of this coefficient shows that the relationship between empowerment and reduced personal accomplishment is reversed.

Sub-hypothesis 4: There is a relationship between job burnout and trust of female teachers.

Correlation coefficient test was used to answer this hypothesis. The results have been inserted in Table (9).

Table 8. Correlation coefficient between job burnout and trust of female teachers

\begin{tabular}{|l|l|l|}
\cline { 2 - 3 } \multicolumn{1}{c|}{} & Job burnout \\
\cline { 2 - 3 } \multicolumn{1}{c|}{} & Correlation coefficient & Significant level \\
\hline \hline Trust & $-0 / 251$ & $0 / 000$ \\
\hline
\end{tabular}

With regard to the above table, the Pearson correlation between job burnout and trust is obtained 0.000 according to the significant level, which is smaller than 0.01 . The null hypothesis is rejected at the 0.01 level and the research hypothesis is confirmed. Therefore, there is a significant relationship between job burnout and trust at $99 \%$ confidence level. Pearson correlation coefficient is 0.251 . The negativity of this coefficient shows that the relationship between job burnout and trust is reversed.

Sub-hypothesis 5: There is a relationship between job burnout and autonomy of female teachers.

Correlation coefficient test was used to answer this hypothesis. The results have been inserted in Table (10).

Table 9. Correlation coefficient between job burnout and autonomy of female teachers

\begin{tabular}{|l|l|l|}
\cline { 2 - 3 } \multicolumn{1}{c|}{} & Job burnout \\
\cline { 2 - 3 } \multicolumn{1}{c|}{} & Correlation coefficient & Significant level \\
\hline \hline Autonomy & $-0 / 266$ & $0 / 000$ \\
\hline
\end{tabular}

With regard to the above table, the Pearson correlation between job burnout and autonomy is obtained 0.000 according to the significant level, which is smaller than 0.01 . The null hypothesis is rejected at the 0.01 level and the research hypothesis is confirmed. Therefore, there is a significant relationship between job burnout and autonomy at $99 \%$ confidence level. Pearson correlation coefficient is 0.266 . The negativity of this coefficient shows that the relationship between job burnout and autonomy is reversed.

Sub-hypothesis 6: There is a relationship between job burnout and effectiveness of female teachers.

Correlation coefficient test was used to answer this hypothesis. The results have been inserted in Table (11).

Table 11. Correlation coefficient between job burnout and effectiveness of female teachers

\begin{tabular}{|l|l|l|}
\cline { 2 - 3 } \multicolumn{1}{c|}{} & Job burnout \\
\cline { 2 - 3 } & Correlation coefficient & Significant level \\
\hline \hline Effectiveness & $-0 / 248$ & $0 / 000$ \\
\hline
\end{tabular}


With regard to the above table, the Pearson correlation between job burnout and effectiveness is obtained 0.000 according to the significant level, which is smaller than 0.01 . The null hypothesis is rejected at the 0.01 level and the research hypothesis is confirmed. Therefore, there is a significant relationship between job burnout and effectiveness at $99 \%$ confidence level. Pearson correlation coefficient is 0.248 . The negativity of this coefficient shows that the relationship between job burnout and effectiveness is reversed.

Sub-hypothesis 7: There is a relationship between job burnout and meaningfulness of female teachers.

Correlation coefficient test was used to answer this hypothesis. The results have been inserted in Table (12).

Table 12. Correlation coefficient between job burnout and meaningfulness of female teachers

\begin{tabular}{|l|l|l|}
\cline { 2 - 3 } \multicolumn{1}{c|}{} & Job burnout \\
\cline { 2 - 3 } & Correlation coefficient & Significant level \\
\hline \hline Meaningfulness & $-0 / 233$ & $\mathbf{0 / 0 0 0}$ \\
\hline
\end{tabular}

With regard to the above table, the Pearson correlation between job burnout and meaningfulness is obtained 0.000 according to the significant level, which is smaller than 0.01 . The null hypothesis is rejected at the 0.01 level and the research hypothesis is confirmed. Therefore, there is a significant relationship between job burnout and meaningfulness at $99 \%$ confidence level. Pearson correlation coefficient is 0.233 . The negativity of this coefficient shows that the relationship between job burnout and meaningfulness is reversed.

Sub-hypothesis 8: There is a relationship between job burnout and merit of female teachers.

Correlation coefficient test was used to answer this hypothesis. The results have been inserted in Table (13).

Table 13. Correlation coefficient between job burnout and merit of female teachers

\begin{tabular}{|l|l|l|}
\cline { 2 - 3 } \multicolumn{1}{c|}{} & Job burnout \\
\cline { 2 - 3 } & Correlation coefficient & Significant level \\
\hline \hline Merit & $-0 / 233$ & $\mathbf{0 / 0 0 0}$ \\
\hline
\end{tabular}

With regard to the above table, the Pearson correlation between job burnout and merit is obtained 0.000 according to the significant level, which is smaller than 0.01 . The null hypothesis is rejected at the 0.01 level and the research hypothesis is confirmed. Therefore, there is a significant relationship between job burnout and merit at $99 \%$ confidence level. Pearson correlation coefficient is 0.233 . The negativity of this coefficient shows that the relationship between job burnout and merit is reversed.

\section{Discussion and Conclusion}

The main hypothesis: There is a significant relationship between job burnout and empowerment of female teachers.

Pearson correlation coefficient and regression analysis were used to investigate this hypothesis. In this hypothesis, empowerment variable has been used as criterion variable and other variables such as job burnout have been used as predictor variables. According to the result interpretation and significance level $(0.000)$ between criterion variable (empowerment) and the predictor variable, i.e. job burnout that is less than 0.05 and according to Pearson correlation coefficient of 0.277 , and negativity of this coefficient, the result shows that the relationship between empowerment and burnout is negative. This means that by increasing/decreasing empowerment, job burnout increases/decreases. According to the results and the negative correlation coefficient, it can be said that there is a negative and indirect relationship between empowerment and job burnout. This means that the lack of empowerment leads to job burnout. In other words, job success can have a significant impact on empowerment. Therefore, it is logical that there is not a direct relationship between empowerment and job burnout. Empowerment programs enable teachers to act in a creative and innovative approach and to present training programs in such a way that they maintain their position in the best way. Work capacities with authority, increasing responsibility, autonomy in decision-making and self-efficacy increase through empowerment programs. As a result, the efficiency and effectiveness of schools are increased. Thus, the infrastructures such as capital, human resources, motivation and attitude are required to achieve empowerment through applying three important principles of teachers' information sharing, determining autonomy framework for decision-making, and replacing self-managed teams in the organization hierarchy. Therefore, the teachers' loyalty and sense of belonging increase that 
is appeared in active participation, innovativeness, and creativity. Eventually, the productivity in education will be improved. The results of this hypothesis are consistent with the researches of Bahrami (2014), Beykzadeh Marzbani and Severi (2007), Sharifipour et al. (2009), Hanson (2001), Wu and Shoot (1996), Rouhollahi (1993), Davoudabadi Farahani (1994).

Sub-hypothesis 1: There is a relationship between emotional exhaustion and empowerment of female teachers.

The research results show that there is an inverse relationship between empowerment and emotional exhaustion through the Pearson correlation coefficient. Regarding the achieved results, since, the Pearson correlation coefficient is 0.253 and according to the significant level $(0.000)$, which is smaller than 0.01 , the null hypothesis is rejected at the 0.01 level and the research hypothesis is confirmed. However, by negativity of Pearson correlation coefficient, it can be said that empowerment shows the lack of an inverse relationship with emotional exhaustion. Considering the low significant level and negativity, Pearson correlation coefficient shows an inverse relationship between the surveyed variables. According to the results, it can be said that empowerment in schools reduces exhaustion among teachers and the results of this hypothesis are aligned with the research results of Bahrami (2014), Payami Busari (1995), Beygifar (1999), Alavi et al. (2009), and they are non-aligned with the research results of Abdi (1994).

Sub-hypothesis 2: There is a relationship between depersonalization and empowerment of female teachers.

The research results show that there is a significant relationship between empowerment and depersonalization through the Pearson correlation coefficient. Regarding the achieved results, since, the significant level is smaller than 0.05 , the research hypothesis is confirmed at 0.05 level. However, by $95 \%$ confidence level, it can be said that there is a significant relationship between empowerment and depersonalization. This means that empowerment in this research has a negative impact on depersonalization. The results of this hypothesis are aligned with the research results of Bahrami (2014), Beygifar (1999), Alavi et al. (2009), Talaei et al. (2007), and Martin (1989) and they are non-aligned with the research results of Abdi (1994).

Sub-hypothesis 3: There is a relationship between reduced personal accomplishment and empowerment of female teachers.

The research results show that there is a significant relationship between empowerment and reduced personal accomplishment through the Pearson correlation coefficient. Regarding the achieved results and the obtained significant level, which is smaller than 0.05 , the research hypothesis is rejected at 0.05 level. This means that empowerment in this research affects the lack of accomplishment. The results of this hypothesis are consistent with the research results of Abdi (1994) and Green (1992). In explaining the sub-hypotheses, it can be said that empowerment is a necessity. The approach base of empowerment is that organizations' employees have high skill and capacity, and organizations' success depends on using this high skill and capacity through advocacy, training, feedback, coaching, delegation of authority, teaming and collaboration, and convert from potentiality to actuality. As a result, empowerment in this research is to promote creativity and to reduce job burnout.

Sub-hypothesis 4: There is a relationship between job burnout and trust of female teachers.

Results showed a significant relationship between job burnout and trust of the female teachers. The result of this hypothesis is consistent with the findings of Bahrami (2014), Fattah (2014), Shaojaei (2014), Damani (2010), Cavus and Demir (2010).

In explaining this result, it can be said that people who rely on others have more preparedness to replace honesty and sincerity by pretense. They are more prone to openness, honesty, and consistency rather than deception and superficiality. In addition, they are more research-oriented, self-organizing, self-confidence, and eager to learn. They have more capacity for interaction and show more cooperation in risk acceptation in groups compared with people with lower trust. People with more trust like others and try to be with others and be an effective part of a group. They also expose themselves and they are more honest in their communication and more capable to listen to others. They are less resistant to change than those with low levels of trust are and they are more capable to adapt to unexpected psychological impacts. More likely, people who trust others are reliable and have high personal ethical standards. Finally, empowered people have a sense called trust and they are sure that they will be treated fairly and equally. They are confident that their result even in a subordinate position would be justice and peace, not harm. Usually, this sense means that they are sure that the power incumbents and authority will not damage them and they will be treated impartially. However, these people maintain their sense of personal confidence even when the powerful people do not show correctness and flexibility. In other words, trust means having a sense of personal security. Trust also implicitly implies that people put themselves in a vulnerable position. However, capable people believe that they will not notice any harm because of their trust. Teachers who experience job burnout have a negative impact on their colleagues both by creating personal conflicts and disruptions in job tasks. Thus, it can be contagious and continue in the form of informal interactions. In addition, one of the impacts of job burnout as a negative contagion is its spreading and affecting people's 
lives. On the other hand, trust making is considered as one of the useful tools to promote the quality of teachers and to increase the organizational effectiveness. In order to succeed in today's changing business environment, organizations require knowledge, ideas, energy and creativity of all employees, ranging from front line employees to high-level managers. However, job burnout can reduce the job performance and interaction with others and increase absenteeism and job quitting.

Sub-hypothesis 5: There is a relationship between job burnout and autonomy of female teachers.

Results showed that there is a significant relationship between job burnout and the autonomy of female teachers. The negativity of this coefficient showed that the relationship is reversed. The results of this research are aligned with the findings of Bahrami (2014), Shaojaei (2014), Damani (2010), Cavus and Demir (2010). To explain this result, it can be said that autonomy has a very direct continuity with the feeling of having a choice about the used method and the amount of effort that needs to be done, the pace of work and time framework of their work. Empower people have a sense of ownership about their work because they can determine how things should be done and how quickly ended. In fact, having the right to choose is the main component is self-organizing. The results showed that the sense of having the right to choose is associated with less alienation in the workplace, greater job satisfaction, higher performance levels, greater creative entrepreneurial activity, and higher levels of job involvement, and less working pressure. In addition, empowered people feel as if they are self-organized. While self-efficacy refers to the sense of ability, and self-organizing attributed to the feeling of having the right to choose. Being self-organized means to experience the feelings of self-selection in implementing and sorting the relevant activities. When people voluntarily and consciously engaged in their duties rather than being forced to engage in business, they feel that they have a choice. Their activities are the result of freedom and personal authority. Empowered people have a sense of responsibility and ownership about their activities. Regarding this research, schools encourage teachers to have innovativeness without pressure, honoring the collective interests with minimal supervision through teacher empowerment. In addition, empowerment is important to hope and dependence teachers during downsizing the organization. Empowerment enables teachers to have more resistance and flexibility to face with problems and threats. Therefore, it can be useful as a source that prevents the vulnerability of teachers and plant the hope seeds in their heart in critical situations such as disposal of financial assets and the loss of human life.

Sub-hypothesis 6: There is a relationship between job burnout and effectiveness of female teachers.

Results showed that there is a significant relationship between job burnout and effectiveness of female teachers and the negativity of this coefficient showed that this relationship is reversed. The result of this hypothesis is aligned with the findings of Fattah (2014), Shojaei (2014), Damani (2010), Cavus and Demir (2010). In explaining this result, it can be said that empowered people have a personal control sense on results. They believe that they can make change by affecting the environment, in which they work or the results to be obtained. Green Berger believes that the sense of being effective is the individual's beliefs within a specified period about hislher ability to create better results. Empowerment helps people to increase their number of activities that they can control. This often depends on the individual's ability in the fields that helshe can affect and influence by hislher ability, volition, and changing the external environment to increase hislher domination.

Sub-hypothesis 7: There is a relationship between job burnout and meaningfulness of female teachers.

Results showed that there is a significant relationship between job burnout and meaningfulness of female teachers and the negativity of this coefficient showed that this relationship is reversed. The result of this hypothesis is aligned with the findings of Bahrami (2014), Fattah (2014), Shojaei (2014), Damani (2010), and Cavus and Demir (2010). In explaining this result, it can be said that empowered people have a sense of being meaningful. They valorize their purpose, objectives or activities, which they are employed. Their ideals and standards are congruent to what they are already doing. Activity is important in their value system. They are careful in what they produce and they believe it. They spend their psychological and spiritual power in their activities and they have a kind of personal importance sense in their engagement. Consequently, they experience transplantation and solidarity in that activity. Therefore, being important is focused on a value-focused attitude. The study about the meaningfulness of the work concluded that people are more committed and involved in their work when they feel the work is meaningful rather than the meaningfulness of the work is low. When they feel the work is meaningful, they focus more energy and show more perseverance in the pursuit of desired goals. Since, meaningful work is associated with sense of personal security and self-worth; they have more enthusiasm in its employment. In addition, those who have been empowered with a sense of meaningful jobs are in higher levels and they are more effective and more efficient than those who have lower rates of job.

Sub-hypothesis 8: There is a relationship between job burnout and merit of female teachers.

Results showed that there is a significant relationship between job burnout and merit of female teachers and the negativity of this coefficient showed that this relationship is reversed. The result of this hypothesis is aligned with the findings of Fattah (2014), Shojaei (2014), Damani (2010), and Cavus and Demir (2010). In explaining this result, it can be 
said that the sense of merit, in fact, is the sense of people with high skills to perform their duties. When people are empowered, they have the sense of merit and they feel that they have the required capability and expertise to carry out their work successfully. Empowered people not only have the sense of merit, but also feel confident that they can do with merit. They have the sense of personal superiority and they believe that while facing challenges they can learn that this feature is the most important empowerment element because having the sense of merit determines that whether people will try to do hard work and have perseverance or not?

Thus, according to the results of the study, the following recommendations can be provided to improve the organizational performance:

1. Considering the first hypothesis about the relationship between empowerment and job burnout, it is recommended that in-service training be held in the Educational Organization for teachers to increase inservice training. The hypotheses results suggest that there is an inverse relationship between empowerment and emotional exhaustion and one of the factors influencing the job burnout (emotional exhaustion) is organizational empowering. This, it is recommended to conduct another research in the field of empowering with variables, related to reducing emotional exhaustion and there is a significant relationship between empowerment with depersonalization and reduced personal accomplishment. Therefore, it is necessary to have further and more accurate investigation in this regard understand the other factors.

2. Considering the first sub-hypothesis results, it is recommended to give more attention from authorities and stakeholders to improve conditions in the workplace given the high amounts of emotional exhaustion and reduced personal accomplishment and the approved role of job burnout in the reduced personal accomplishment.

3. Considering the second sub-hypothesis results, it is recommended that attention to the views of employees and imposing their preferences and opinions as much as possible by the authorities can be effective to improve their efficiency and reduce burnout aspects. It is recommended that this study be conducted among the employees of other organizations and better measures and strategies be implemented to promote mental and physical health of employees in schools and to reduce their job burnout.

4. Considering the third sub-hypothesis results, it seems that other personal factors such as values, general mental ability, etc. can affect job burnout as a personal factor. Therefore, it is recommended that other researches be conducted in the field of empowerment and failure of personal success.

5. Considering the fourth sub-hypothesis results, empowered people have a sense called trust. They are sure that they will be treated fairly and equally. These people maintain this ensure that their work result even in the lower levels will be justice and peace instead of harm. Usually, this sense means that they are sure that the power center authorities will not damage them and they will be treated fairly. However, even when powerful people do not show accuracy and flexibility, empowered people maintain their self-confidence. In other words, trust is having a sense of personal security. Considering the findings, it is recommended that further study of the causes of job burnout and adopting measures in the field of prevention, control, training the right methods and skills to deal with stress and address factors underlying this phenomenon are considered necessary. Therefore, it is recommended to have a special attention and trust to people and workplace adornment, to implement the recommendations, to create motivational facilities and job enrichment, to attention to training and authority, to create warmth and camaraderie atmosphere among employees, to clarify the role and duties of employees, to organize a performance assessment system in the office, availability of excellent management organization, to have an intimate relationship with employees, to reform the organizational structure in order to increase flexibility and self-confidence, to provide resources and physical facilities and administrative equipment, to encourage and award and appreciate deserve employees, to create the required growth and learning opportunities for employees, to hold continuous and specialized training courses about the tasks that are assigned to them.

6. Considering the fifth sub-hypothesis results, empowered people have a sense of self-organizing while selfefficacy refers to the sense of having ability. Self-organization is related to the feeling of having the right to choose. Being self-organized means to experience the sense, choosing components and organizing the related activities. When people voluntarily and consciously engaged in their duties rather than being forced to engage in business, they have the feeling of self-organization. Their activities are the consequence freedom and personal authority. Therefore, it is suggested to examine the aspect of autonomy (self-organizing) from different angles. Organizations that wish to implement empowerment should be quite familiar with its concept. Based on the results, most of the teachers think that they are familiar with the concept of empowerment while only a few teachers are familiar with its concept and its application. 
7. Considering the sixth sub-hypothesis results, empowered people believe that they can make change by affecting the environment, in which they work or the results that they achieve. People who have effectiveness feeling try to maintain it instead of having reactive behavior against what they see. Having the sense of effectiveness in the work is completely related to the sense of self-controlling. To having the sense of empowerment, people not only should feel that what they do has a reaction, but also should feel that they can make it by themselves. This means that they can control the result to associate those results with the sense of empowerment. Researches about the personal control show that people are motivated internally to seek their personal control. They fight to maintain their sense of control and success. Therefore, it is recommended that teacher leave their chores to empowered groups. However, objectives must be expressed for them previously and the necessary tools such as information and resources must be provided for them. Then, the manager has an opportunity to work more crucial.

8. Considering the seventh sub-hypothesis results, empowered people have the sense of meaningfulness. They valorize their purpose, objectives or activities, which they are employed. Their ideals and standards are congruent to what they are already doing. Activity in their value system is considered important. They are careful in what they produce and they believe it. They spend their psychological and spiritual power in their activities and they have a kind of personal importance sense in their engagement. Consequently, they experience transplantation and solidarity in that activity. Therefore, being important is focused on a valuefocused attitude. Therefore, it is suggested to conduct another research in this field.

9. Considering the eighth sub-hypothesis results, when people become empowered, they have the sense of selfeffectiveness, or they feel that they have the required ability and expertise to do a successful work. Empowered people not only feel competent, but also confident that they can do the work with adequacy. They have the sense of personal superiority and they believe that they can learn and growth to cope with new challenges.

\section{References}

A Whetten, David Cameron (1999), empowerment and delegation of authority, translated by Badrodin Avraei, Institute of Research and Training Administration of the Ministry of Energy.

Bahrami, Maryam (2014), the role of psychological empowerment and organizational commitment on job burnout of teachers, Journal of School Psychology, Volume 3, Issue 1, Pages 37-54.

Hassani, Fatemeh. (2002), evaluating the amount of job burnout of mathematics and art female teachers in ordinary schools in Tehran, Master Thesis, University of Al-Zahra, Faculty of Education and Psychology, Educational Psychology field.

Saatchi, Mahmoud (2007) Industrial and Organizational Psychology. Edition

Shojaei, Manny (2014), evaluating the effect of psychological empowerment on reducing job burnout given the perceived organizational support role in insurance companies of Tehran, the first National Conference on Research and Development in the Third Millennium.

Fattah, Nazem (2014), relationship between empowerment and quality of work life with job burnout in the employees the educational system of Tehran, a new approach in educational administration, Volume 5, Issue 2, Pages 91-108.

O'Brien, J. L. (2010). Structural empowerment, psychological empowerment and burnout in registered staff nurses working in outpatient dialysis centers. Rutgers the State University of New Jersey - Newark. Unpublished Doctoral Dissertation. 